Click www.researchjournal.co.in/online/subdetail.html to purchase.

Visit Us - www.researchjournal.co.in D DOI : 10.15740/HAS/IRJAES/6.1/210-217

International Research Journal of Agricultural Economics and Statistics Volume 6 | Issue 1 | March, 2015 | 210-217 [ e ISSN-2231-6434 |

\title{
A Case $\mathbf{S}$ tudy $\quad$ Rice marketing - A macro and micro analysis
}

\section{UMA GOWRI}

\section{Correspondence to :}

M. UMA GOWRI

Centre for Agricultural and

Rural Development

Studies, Tamil Nadu

Agricultural University,

COIMBATORE (T.N.) INDIA

Email: umanomics@gmail.

com
KEY WORDS : Marketing, Price spread, Efficiency, Farmers share, Rice production

HOW TO CITE THIS PAPER : Gowri, M. Uma (2015). Rice marketing - A macro and micro analysis. Internat. Res. J. Agric. Eco. \& Stat., 6 (1) : 210-217.

Paper History : Received : 09.01.2015; Accepted : 23.02.2015 